\section{Multiplex PCR: Advantages, Development, and Applications}

\section{Mary C. Edwards and Richard A. Gibbs}

Institute for Molecular Genetics, Baylor College of Medicine, Houston, Texas 77030
Ever since it was shown that PCR could simultaneously amplify multiple loci in the human dystrophin gene, ${ }^{(1)}$ multiplex PCR has been firmly established as a general technique. A short list of multiplex PCR applications now includes pathogen identification, gender screening, linkage analysis, forensic studies, template quantitation, and genetic disease diagnosis. Multiplex PCR can be a two-amplicon system or it can amplify 13 or more separate regions of DNA. It may be the end point of analysis, or preliminary to further analyses such as sequencing or hybridization. The steps for developing a multiplex PCR and the benefits of having multiple fragments amplified simultaneously, however, are similar in each system.

This review focuses on multiplex systems in which each primer pair targets a single locus, unlike RAPD ${ }^{(2)}$ and alumorph ${ }^{(3)}$ PCR reactions, which amplify multiple loci with a single primer or primer set.

\section{ADVANTAGES OF MULTIPLEX PCR Internal Controls}

Potential problems in PCR include false negatives due to reaction failure or false positives due to contamination. False negatives are often revealed in multiplex amplification because each amplicon provides an internal control for the other amplified fragments. For example, multiple exons may be amplified in assays that survey for gene deletion. Unless the entire region scanned by the multiplex PCR is deleted, amplification of some fragment(s) indicates that the reaction has not failed (Fig. 1A). Furthermore, because major deletions are usually contiguous, ${ }^{(4)}$ results that suggest noncontiguous deletions based on the absence of bands usually reflect artifactual failure of some fragments to amplify. Complete PCR failure can be distinguished from an informative no-amplification result by adding a control amplicon external to the target sequence to the reaction. ${ }^{(5,6)}$ In addition to monitoring PCR failure and artifacts, internal control amplicons can be designed to verify the presence of target template. In multiplex assays where closely related templates such as pathogen strains are distinguished by amplifying differing sequence, primers for a sequence common to all templates provide a positive control for amplification. ${ }^{(7-11)}$

\section{Indication of Template Quality}

The quality of the template may be determined more effectively in multiplex than in single locus PCR. Degraded templates give weaker signals for long bands than for short. ${ }^{(4)} \mathrm{A}$ loss in amplification efficiency due to PCR inhibitors in the template samples can be indicated by reduced amplification of an abundant control sequence in addition to the amplification of rarer target sequences in an otherwise standardized reaction. ${ }^{(12)}$

\section{Indication of Template Quantity}

The exponential amplification and internal standards of multiplex PCR can be used to assess the amount of a particular template in a sample. To quantitate templates accurately by multiplex PCR, the amount of reference template, the number of reaction cycles, and the minimum inhibition of the theoretical doubling of product for each cycle must be accounted. ${ }^{(13)}$ In the simplest method of quantitation, the gene multiplexes for major deletions detect carriers or duplications in probands when the band intensity of abnormal amplicons is compared with that of normal, homozygous fragments in the multiplex (Fig. 1B). ${ }^{(14-17)}$ Cycling conditions for carrier testing must be determined carefully, because the variation in amplicon intensities will be masked if the reaction is allowed to cycle until the signal is saturated. ${ }^{(18)}$ The diagnosis is most accurate when at least two other fragments are used in the 


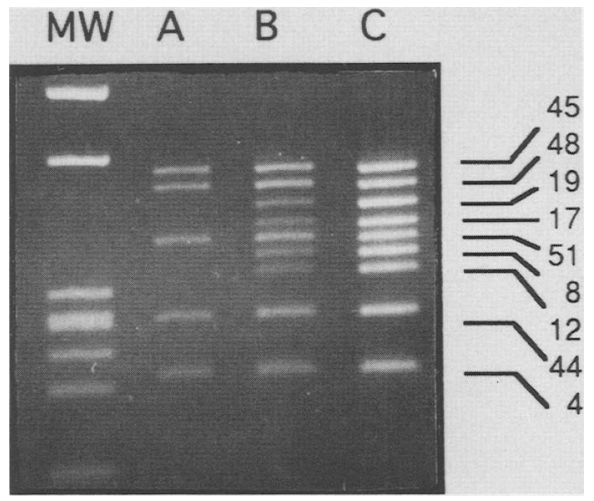

FIGURE 1 Multiplex amplification of 9 exons in the human dystrophin gene. ${ }^{(15)}$ The normal pattern of amplification, indicating the presence of these exons in the patient, is shown in lane $C$. Lane $A$ is missing bands corresponding to exons $8,12,17$, and 19 , suggesting that the patient has a deletion in the region of exons 8-19. The presence of some amplified bands serves to delineate the extent of the deletion and to indicate that the reaction has not failed. Lane $B$ shows bands with approximately half the intensity for the exons that were not amplified in patient $A$, suggesting that this patient is a carrier for a deletion in that region. This demonstrates potential for a simple method of quantifying templates by multiplex PCR. The molecular weight marker is $\Phi \times 174$ DNA digested with HaelII.

comparison ${ }^{(16)}$ and the analysis is performed by densitometry, fluorescent scanning on an automated DNA sequencer, or by analysis of charge coupled device camera images. ${ }^{(19)}$ Preliminary studies suggest that signal intensities of fluorescent multiplex PCR products may reflect relative amounts of mixed, disproportionate DNAs in forensic samples. ${ }^{(20)}$

The majority of multiplex quantitation assays compare the signal intensity of a reference sequence to the signal from another sequence in the same reaction, either directly or by extrapolating the result to standard curves. ${ }^{(13)}$ There are numerous coamplification assays based on this principle in the literature of competitive PCR with RNA or DNA standards.

\section{Efficiency}

The expense of reagents and preparation time is less in multiplex PCR than in systems where several tubes of uniplex PCRs are used. A multiplex reaction is ideal for conserving costly polymerase and templates in short supply. For maximum efficiency of preparation time, the reactions can be prepared in bulk, randomly tested for quality, and stored frozen without enzyme or template until use. ${ }^{(1)}$

\section{DESIGN AND DEVELOPMENT OF MULTIPLEX PCR}

Producing some multiplex PCR systems may be as simple as combining two sets of primers for which reaction conditions have been determined separately. However, other multiplex PCRs must be developed with careful consideration for the regions to be amplified, the relative sizes of the fragments, the dynamics of the primers, and the optimization of PCR technique to accommodate multiple fragments. These steps, which are discussed in detail below, are outlined in Table 1.

\section{Selection of Multiplex Loci}

The regions selected for multiplex amplification may be determined by the nature of the analysis; for example, deletion assays amplify exons, forensic assays distinguish individual variation at highly polymorphic markers, and microbial assays may exploit strain- or species-specific variation. The type of 
Table 1. Step-by-Step Development of a Multiplex PCR System

\section{Choose Loci}

Determine PCR system.

Distribute amplicons (localized at mutation hot spots, linked to genes, chromosomally unlinked, grouped close exons in a single amplicon, etc.).

Design internal control fragment(s) (other exons, external sequences, host sequence, sequence conserved in all target templates, etc.).

2. Position Primers in regions of detailed sequence; in relation to amplicon sizes.

3. Design Primers with similar reaction kinetics.

4. Develop PCR Conditions Separately for each primer set.

5. Add Primer Sets Sequentially, altering conditions as necessary. Reduce nonspecific amplification (hot start, ionic detergents, short extension times, hottest annealing, reselect primer sequence). Vary relative concentrations of primer sets for equal amplification. Change buffer systems if necessary.

6. Adjust reaction components and cycling conditions for multiplex amplification. $\mathrm{Mg}^{2+}$, $\mathrm{dNTP}$, and polymerase requirements may increase. Ideal extension times may be longer.

analysis to be done may lend itself to a PCR technique that was originally applied to uniplex amplification but that can be adapted for multiplex purposes, such as allele-specific PCR, ${ }^{(21,22)}$ restriction site-generating PCR, ${ }^{(23-25)}$ amplification refractory mutation system (ARMS), ${ }^{(26-29)}$ color complementation assay, ${ }^{(30)}$ and nested PCR. ${ }^{(6,31,32)}$ For deletion assays of genes with many exons, the amplicons can be distributed to scan a wide region or a concentrated region at deletion hot spots. Close exons can be amplified by a pair of primers spanning both. ${ }^{(15)}$ Multiplex amplicons that distinguish similar templates, such as virus types, bacteria strains, or gene alleles, are ideally located in regions that are not extremely variable, where any given amplicon might contain the sequence of several genotypes ${ }^{(32}$. Unlike the exon-specific multiplexes in which multiple signals provide built-in positive controls, other multiplexes, such as those identifying pathogens, rely on a differential signal to distinguish templates and so benefit from an additional primer set to provide an internal control.

\section{Positioning of Primers}

Detailed sequence information for primer sites at the selected loci is important, because nonspecific amplification may occur at other sites with similar sequences, ${ }^{(18)}$ or reduced amplification may occur at primer-template mismatched sites. ${ }^{(31)}$ Primers for exon-amplifying multiplexes are ideally placed in intronic sequences adjacent to the exons. This provides some margin for adjustment of fragment length or amplification quality as well as possible information about alterations affecting splice sites ${ }^{(1)}$ If the multiplex product is to be resolved electrophoretically, fragment sizes should be selected so that they may be separated easily from each other. The range of band sizes should not be so wide that all fragments cannot be resolved well on the same gel. However, with the use of fluorescently labeled primers, product ranges may overlap and yet be distinguished by color. ${ }^{(20,30,33,34)}$ Fluorescently-labeled multiplex primers aid diagnostics by representing product amounts more accurately than ethidium bromide stain and by reducing reaction time and nonspecific amplification with the fewer PCR cycles needed to obtain a signal. ${ }^{(18)}$

\section{Developing Primers and Reaction Conditions}

Primer sequences should be designed so that their predicted hybridization 
kinetics are similar to those of other primers in the multiplex reaction. A G/C content of $40-60 \%$ and a length of 23-28 nucleotides are suggested as general guidelines for specific annealing at moderate temperatures. ${ }^{(35)}$ Primer annealing temperatures and concentrations may be calculated to some extent, but conditions will almost certainly have to be refined empirically in multiplex. Conditions for each set of primers should be developed individually and modified if necessary as primer sets are added. Primer pairs that work separately but not when combined may be improved by a prior ethanol precipitation in $0.3 \mathrm{M}$ sodium acetate. ${ }^{(36)}$ The possibility of nonspecific priming and other artifacts is increased with each additional primer. Thus, primer pairs that give a "clean" signal alone but produce artifact bands in multiplex may benefit from "hot-start" $\mathrm{PCR},{ }^{(31)}$ addition of organics, annealing at the highest possible temperature, or, if all else fails, reselection of the primer sequence. ${ }^{(18)}$

If equimolar primer concentrations do not yield uniform amplification signals for all fragments, the concentration of some primer pairs can be reduced in relation to others. This is particularly important in samples where one target is more abundant than others. ${ }^{(37)}$ An inverse relation between the required oligonucleotide concentration in multiplex PCR and its $\mathrm{A} / \mathrm{T}$ content, but not its length or melting temperature, has been suggested. ${ }^{(31,38)}$

When all primer pairs are not compatible it may be necessary to subgroup them in smaller multiplexes. ${ }^{(39)}$ However, an earlier maximum of 18 primers in a multiplex ${ }^{(14)}$ has been surpassed recently by a dystrophin gene multiplex containing 26 primers $^{(40)}$ by further optimizing reaction conditions.

\section{Titration of Reaction Components}

It may be necessary to adjust concentrations of various reaction components to achieve a robust multiplex PCR. $\mathrm{Mg}^{2+}$ and $\mathrm{dNTP}$ requirements generally increase with the number of amplicons in the multiplex, but the concentrations must be optimized because each primer pair may have different requirements. ${ }^{(18)}$ Likewise, polymerase requirements generally increase with the size of the multiplex. ${ }^{(18)}$ Buffer systems may affect amplification dramatically. For example, the buffer recommended by the Cetus Corporation allows complete amplification of normal DNA in one Duchenne muscular dystrophy (DMD) 9-exon multiplex ${ }^{(36)}$ but not in another. ${ }^{(14)}$ Dimethylsulfoxide was found to be a beneficial ingredient ${ }^{(22,38)}$ or an inhibitor ${ }^{(31)}$ in different multiplex systems. Other additives that minimize nonspecific binding in multiplex PCR are Tween 20 and Triton $X-100,{ }^{(6)} \beta$-mercaptoethanol, ${ }^{(1,15,41)}$ and tetramethylammonium chloride. ${ }^{(22)}$

\section{Adapting Thermocycling Conditions}

Thermocycling parameters are also determined largely by the sequence of the primer sets. Generally, extension times should be increased with the number of loci amplified in the reaction. ${ }^{(18)}$ However, long extension and annealing times could provide opportunity for nonspecific amplification. ${ }^{(18)}$

\section{Competition and Interference}

An aspect of PCR that may be exacerbated in multiplex is competition for resources and resulting artifacts. Differences in the yields of unequally amplified fragments are enhanced with each cycle. ${ }^{(27)}$ Sets of amplicons of varying lengths but similar sequence may show preferential amplification of the shortest, particularly if they share a common primer. This may be due to limited processivity or suppressed amplification of the outer, longer amplicon by the inner, shorter one when primers anneal on the same strand. ${ }^{(32)}$ 
This effect can be circumvented by initiating PCR with the long amplicon primers and by adding the primer for the shorter some cycles later, ${ }^{(42)}$ or by using a low concentration of the short amplicon primer. ${ }^{(32)}$ In multiplex PCR of homologous amplicons with very similar lengths and no shared primers, no competition was reported. ${ }^{(43)}$ Suppressed amplification of one amplicon by another has been noted in a multiplex in which sequence and primers were not shared, ${ }^{(7)}$ but coamplification was resolved by initiating the limited amplicon several cycles before the other.

Primer-template mismatches have been noted to be at a disadvantage relative to perfect matches in multiplex, presumably due to competition for binding to the polymerase. ${ }^{(31)}$ When an ambiguous negative result for the presence of multiple HIV-1 sequences was suggested at a mismatched site, a uniplex of the failed amplicon generated a product. ${ }^{(31)}$

Multiple sets of primers increase the possibility of primer complementarity at the 3 ' ends, leading to "primer-dimers." These artifacts deplete the reaction of dNTPs and primers and outcompete the multiplex amplicons for polymerase. ${ }^{(38,42)}$ This effect can be reduced by titrating primer concentrations and cycling conditions.

\section{POST-PCR ANALYSIS}

More extensive analysis than gel electrophoresis of multiplex products is requisite for some systems, particularly those that identify point mutations or other small alterations. Additionally, the complexity of some multiplex reactions makes verification of specific PCR products by such methods as probing and sequencing desirable, even if limited to the development phase. Many of the techniques for product analysis developed for uniplex PCR can be applied directly to multiplex PCR.

A second multiplex reaction can be generated by using the product of the first as a template when high specificity is required. ${ }^{(31)}$ Alternatively, the second reaction may be based on the results of the first. In an example of the latter, carrier diagnosis is made by multiplexed simple tandem repeats (STRs) if deletions are not found by DMD exon multiplex PCR. ${ }^{(44,45)}$ Uniplex reactions may be generated from multiplex, ${ }^{(6,15,46)}$ or vice versa. ${ }^{(32)}$

The product of a multiplex PCR may be sequenced to reveal new mutations or small alterations where major deletions are not present. This may be done directly from the multiplex reaction product, ${ }^{(43,47)}$ or the product may require further preparation prior to sequencing. The introduction of biotinylated and universal-tailed primers in nested PCR following multiplex allows solid-phase sequencing of exons and flanking intronic sequence for small alterations. ${ }^{(15,46)}$ Other multiplex reactions have been subcloned prior to sequencing in the development phase. ${ }^{(32,48)}$

Treatment with restriction enzymes, ${ }^{(6,23-25,29,49,50)}$ hybridization of product and probe, ${ }^{(12,37,51-56)}$ and single-strand conformational polymorphism (SSCP) analysis ${ }^{(41,47,57)}$ are also used routinely to analyze multiplex PCR products. The choice of the particular method is guided by the sequence of the amplified fragments. For example, mutations that abolish restriction sites may be detected by enzymatic digestion, whereas broad screening for sequence variants may be accomplished by SSCP. Finally, PCR multiplex products can be of use as a molecular weight ladder because the lengths of the amplified fragments are known.

\section{APPLICATIONS OF MULTIPLEX PCR}

\section{Gene Deletion and Mutation Detection}

Major deletion multiplexes of X-linked human disease genes are designed to give positive or negative indication of the presence of an exon. The hypoxanthine phosphoribosyltransferase gene multiplex for Lesch-Nyhan syn- 
drome $^{(15)}$ and the $\alpha$-galactosidase A gene multiplex for Fabry disease ${ }^{(58)}$ each amplifies all coding regions. However, dystrophin gene multiplexes for Duchenne/Becker muscular dystrophy (DMD/BMD) ${ }^{(14,16,36,59)}$ concentrate on hotspot regions of deletion. The steroid sulfatase gene multiplex detects what are frequently whole-gene deletions. ${ }^{(5)}$ These reactions can provide a template for the detection of finer alterations if major deletions are not identifed in a sample. ${ }^{(15,46,57)}$

Mutations and small deletions in genes are detected by multiplex assays either directly by PCR or by subsequent analysis of PCR products. Results may be determined immediately by gel electrophoresis for RB1 gene exons amplified to reveal small deletions causing retinoblastoma ${ }^{(48)}$ and for multiplex ARMS reactions of common population-specific $\beta$-thalassemia ${ }^{(26,28)}$ and cystic fibrosis ${ }^{(21,27)}$ mutations. Several mutation types may be examined simultaneously, as in a multiplex reaction that detects a point mutation, a 4-base deletion, and complete deletion of the $\alpha$-globin genes. ${ }^{(30)}$

Other mutation-amplifying multiplexes rely on post-PCR manipulation of the reaction product for diagnosis. SSCP detects human p53 tumor suppressor gene mutations associated with breast cancer. ${ }^{(41)}$ Cycle sequencing reveals activation mutations in mouse ras oncogenes. ${ }^{(43)}$ Techniques to identify the numerous, often population-specific, mutations in the cystic fibrosis transmembrane conductance regulator gene have spawned several multiplex systems: hybridization of exons to mutation-specific oligonucleotides; ${ }^{(52-54)}$ restriction enzyme digestion of natural restriction sites at amplified mutations ${ }^{(49)}$ or at primer-created restriction sites; ${ }^{(23-25)}$ and use of allelespecific primers. ${ }^{(21)}$

Genotyping by multiplex PCR employs similar techniques. ABO blood group alleles are distinguished by allele-specific primers ${ }^{(22)}$ or by enzymatic digestion of amplified product. ${ }^{(50)}$ HLA-DR4 variants, associated with autoimmune diseases, are typed by multiplex ARMS. ${ }^{(29)}$

Multiplex PCR of sequence tagged sites has aided the physical mapping of breakpoints and loci on chromosome 16 using somatic cell hybrids ${ }^{(39)}$ and of the $\mathrm{X}$ chromosome in deletion patients. ${ }^{(60)}$ Other mapping applications are discussed below.

\section{Polymorphic Repetitive DNA}

Repetitive DNA polymorphisms are multiplexed for mapping, disease linkage, gender determination, and DNA typing/identification. Short tandem repeats (STRs) of 1-6 bp are convenient for multiplexing because they are numerous, highly polymorphic, ${ }^{(61)}$ and may be coamplified without overlapping size ranges. ${ }^{(62)}$ Multiplexes of relatively close repeats are employed for disease linkage, but chromosomally unlinked repeats are used for the identification of individuals. ${ }^{(33)}$

Multiplex PCR is an ideal technique for DNA typing because the probability of identical alleles in two individuals decreases with the number of polymorphic loci examined. Reactions have been developed with potential applications in paternity testing, forensic identification, and population genetics. ${ }^{(20,33,62)}$

Multiplexed polymorphic repeats determine whether family members have inherited an identical chromosome to the proband. Generally, diagnosis by STR markers is performed when assays to locate the mutation directly, such as the gene multiplex PCRs described above, are not informative. These assays lend themselves to multiplexing because examination of more than one marker linked to the disease gene reduces the possibility of missing recombination events and because occasional new mutations in an STR marker might suggest a mistyped or mislabeled individual unless other markers are examined. ${ }^{(63)}(\mathrm{CA})_{n}$ Repeats have been multiplexed for the diagnosis of 
myotonic dystrophy, ${ }^{(63)} \mathrm{DMD},{ }^{(44,45)}$ cystic fibrosis, ${ }^{(64,65)}$ and Prader-Willi/Angelman syndromes. ${ }^{(66)}$ STRs multiplexed for examining potential associations of $V b 6$ human T-cell receptors with disease led to the identification of new gene family members. ${ }^{(56)}$

Genetic mapping with multiplex amplified STRs can augment physical mapping. Comparison of recombination frequencies among markers indicates their relative positions. Multiplex PCR aided the ordering of tightly linked chromosome 9 repeats, ${ }^{(67)}$ and numerous $\mathrm{X}$ chromosome (CA) ${ }_{n}$ repeats have been mapped. ${ }^{(60,69)}$ Such multiplexes may also assist the physical mapping of yeast artificial chromosomes. ${ }^{(33)}$

Repetitive DNA loci are incorporated in gender-determining multiplex assays. Embryos of families with $X$-linked disease can be sexed by coamplifying a Y-specific repetitive DNA locus with a gene sequence on both $\mathrm{X}$ and $\mathrm{Y}$ chromosomes; ${ }^{(6)}$ multiplex results are confirmed by subsequent analyses. The Y-specific STR is amplified with an X-specific STR in a multiplex for forensic specimens. ${ }^{(70)}$

\section{Microbe Detection and Characterization}

PCR analysis of bacteria is advantageous, as the culturing of some pathogens has been lengthy or not possible. Bacterial multiplexes indicate a particular pathogen among others, or distinguish species or strains of the same genus. An amplicon of sequence conserved among several groups is often included in the reaction to indicate the presence of phylogenetically or epidemiologically similar, or environmentally associated, bacteria and to signal a functioning PCR. Multiplex assays with this format distinguish species of $\mathrm{Le}^{-}$ gionella, ${ }^{(7)}$ Mycobacterium, ${ }^{(10)}$ Salmonella ${ }^{(11)}$ Escherichia coli, and Shigella ${ }^{(8)}$ and major groups of Chlamydia ${ }^{(9)}$ from other genus members or associated bacteria. An assay for Mycobacterium leprae coamplifies human and pathogen DNA. ${ }^{(12)}$ Multiplex assays differentiate forms of the insecticidal protein crystal-producing Bacillus thuringiensis, ${ }^{(42)}$ Shiga-like toxin-producing E. coli, ${ }^{(71)}$ and yeast. ${ }^{(72)}$

Viral DNA is amplified by multiplex PCR to screen tissue samples or to examine associations of infection with disease. A fragment from the host genomic DNA is generally coamplified in these assays. ${ }^{(31,37,38)}$ Human papillomavirus (HPV) associations with carcinomas or lesions, ${ }^{(73,74)}$ and adenovirus 12 with celiac disease, ${ }^{(51)}$ have been examined. Multiplex assays detect or screen for HPV, ${ }^{(38)}$ human immunodeficiency virus type 1 (HIV-1) and human T-cell leukemic viruses, ${ }^{(37)}$ human $T$ lymphotrophic virus types I and $\mathrm{II},{ }^{(55)}$ hepatitis B virus, ${ }^{(32)}$ parvovirus B19, ${ }^{(75)}$ and hog cholera viruses. ${ }^{(76)}$ HIV-1 infection can be detected by nested multiplexes of conserved regions. ${ }^{(31)}$

\section{CONCLUSIONS AND FUTURE PROSPECTS}

The properties of multiplex PCR, including internal controls, indications of template quantity and quality, and less expense of time and reagents, make the technique a useful general tool and preferable to simultaneous uniplex PCR in many instances. Multiplex PCR methods exhibit great flexibility in experimental design and in overcoming limiting primer kinetics and fragment competition. A number of uniplex PCR techniques have been adapted to multiplex amplification for diagnosis of genetic and infectious disease; for identification of persons, populations, and pathogens; and to aid in revealing the organization of the human genome.

Given the usefulness already demonstrated by multiplex PCR, future applications should be numerous. Maximizing the number of regions that may be concurrently amplified would have practical applications in genetic dis- 
ease diagnosis at loci without apparent mutation hot spots or with many new mutations, and at which population-specific mutations have necessitated the development of multiplex reactions oriented to single populations. Multiplex amplification should be ideal whenever two or more sequences are examined by PCR for associations such as genetic linkage, environmental associations, and host-parasite and disease-infection relationships. The general refining of the PCR technique may be aided by multiplex amplification in that each additional primer set in the reaction often provides a challenge to optimize the technique. Multiplex quantitation systems also provide information on the PCR technique by revealing influences on the exponential generation of product.

\section{REFERENCES}

1. Chamberlain, J.S., R.A. Gibbs, J.E. Ranier, P.N. Nguyen, and C.T. Caskey. 1988. Deletion screening of the Duchenne muscular dystrophy locus via multiplex DNA amplification. Nucleic Acids Res. 16: 11141-11156.

2. Williams, J.G.K., A.R. Kubelik, K.J. Livak, J.A. Rafalski, and S.V. Tingey. 1990. DNA polymorphisms amplified by arbitrary primers are useful as genetic markers. Nucleic Acids Res. 18: 6531-6535.

3. Zietkievicz, E., M. Labuda, D. Sinnett, F.H. Glorieux, and D. Labuda. 1992. Linkage mapping by simultaneous screening of multiple polymorphic loci using Alu oligonucleotide-directed PCR. Proc. Natl. Acad. Sci. 89: 8448-8451.

4. Chamberlain, J.S. and 33 coauthors. 1992. Diagnostic of Duchenne and Becker muscular dystrophies by polymerase chain reaction: A multicenter study. I. Am. Med. Assoc. 267: 26092615.

5. Ballabio, A., J.E. Ranier, J.S. Chamberlain, M. Zollo, and C.T. Caskey. 1990. Screening for steroid sulfatase (STS) gene deletions by multiplex DNA amplification. Hum. Genet. 84: 571573.

6. Levinson, G., R.A. Fields, G.L. Harton, F.T. Palmer, A. Maddelena, E.F. Fugger, and J.D. Schulman. 1992. Reliable gender screening for human preimplantation embryos, using multiple DNA target-sequences. Hum. Reprod. 7: 1304-1313.

7. Bej, A.K., M.H. Mahbubani, R. Miller, J.L. DiCesare, L. Haff, and R.M. Atlas. 1990. Multiplex PCR amplification and immobilized capture probes for detection of bacterial pathogens and indicators in water. Mol. Cell. Probes 4: 353-365.

8. Bej, A.K., S.C. McCarty, and R.M. Atlas. 1991. Detection of coliform bacteria and Escherichia coli by multiplex polymerase chain reaction: Comparison with defined substrate and plating methods for water quality monitoring. Appl. Environ. Microbiol. 57: 1473-1479.

9. Kaltenboek, B., K.G. Kansoulas, and J. Storz. 1992. Two-step polymerase chain reactions and restriction endonuclease analyses detect and differentiate ompA DNA of the Chlamydia spp. J. Clin. Microbiol. 30: 1098-1104.

10. Wilton, S. and D. Cousins. 1992. Detection and identification of multiple mycobacterial pathogens by DNA amplification in a single tube. PCR Methods Applic. 1: 269-273.

11. Way, J.S., K.L. Josephson, S.D. Pillai, M. Abbaszadegan, C.P. Gerba, and I.L. Pepper. 1993. Specific detection of Salmonella spp. by multiplex polymerase chain reaction. Appl. Environ. Microbiol. 59: 1473-1479.

12. van der Vliet, G.M., C.J. Hermans, and P.R. Klatser. 1993. Simple colorimetric microtiter plate hybridization assay for detection of amplified Mycobacterium leprae DNA. J. Clin. Microbiol. 31: $665-670$.

13. Ferre, F. 1992. Quantitative or semi-quantitative PCR: Reality vs. myth. PCR Methods Applic. 2: 1-9.

14. Chamberlain, J.S., R.A. Gibbs, J.E. Ranier, P.N. Nguyen, and C.T. Caskey. 1989. Multiple PCR for the diagnosis of Duchenne muscular dystrophy. In PCR protocols, a guide to methods and applications (ed. D.H. Gelfand, M.A. Innis, J.J. Sninsky, and T.J. White), pp. 272-281. Academic Press, San Diego, CA.

15. Gibbs, R.A., P.N. Nguyen, A. Edwards, A.B. Civitello, and C.T. Caskey. 1990. Multiple DNA deletion detection and exon sequencing of the hypoxanthine phosphoribosyltransferase gene in Lesch-Nyhan families. Genomics 7: 235-244.

16. Abbs, S. and M. Bobrow. 1992. Analysis of quantitative PCR for the diagnosis of deletion and duplication carriers in the dystrophin gene. J. Med. Genet. 29: 191-196.

17. Ioannou, P., G. Christopoulos, K. Panayides, M. Kleanthous, and L. Middleton. 1992. Detection of Duchenne and Becker muscular dystrophy carriers by quantitative multiplex polymerase chain reaction analysis. Neurology 42: 1783-1790.

18. Chamberlain, J.S., R.A. Gibbs, J.E. Ranier, and C.T. Caskey. 1991. Detection of gene deletions 
using multiplex polymerase chain reactions. In Methods in molecular biology, vol. 9: Protocols in human molecular genetics (ed. C. Mathew), pp. 299-312. The Humana Press, Clifton, NJ.

19. Metzger, M., personal communication.

20. Klimpton, C.P., P. Gill, A. Walton, A. Urquhart, E.S. Millican, and M. Adams. 1993. Automated DNA profiling employing multiplex amplification of short tandem repeat loci. PCR Methods Applic. 3 13-21.

21. Fortina, P., R. Conant, G. Monokian, G. Dotti, T. Parrella, W. Hitchcock, J. Kant, T. Scanlin, E. Rappaport, and E. Schwartz. 1992. Non-radioactive detection of the most common mutations in the cystic fibrosis transmembrane conductance regulator gene by multiplex polymerase chain reaction. Hum. Genet. 90: 375-378.

22. Uggozoli, L. and B. Wallace. 1992. Application of an allele-specific polymerase chain reaction to the direct determination of ABO blood group genotypes. Genomics 12: 670-674.

23. Ng, I.S.L., R. Pace, M.V. Richard, K. Kobayashi, B. Kerem, L.-C. Tsui, and A.L. Beaudet. 1991. Method for analysis of multiple cystic fibrosis mutations. Hum. Genet. 87: 613-617.

24. Cremonesi, L., E. Belloni, C. Magnani, M. Seia, and M. Ferrari. 1992. Multiplex PCR for rapid detection of three mutations in the cystic fibrosis gene. PCR Methods Applic. 1: 297-298.

25. Gasparini, P., A. Bonizzato, M. Dognini, and P.F. Pignatti. 1992. Restriction site generatingpolymerase chain reaction (RG-PCR) for the probeless detection of hidden genetic variation: Application to the study of some common cystic fibrosis mutations. Mol. Cell. Probes 6: 1-7.

26. Beinvenu, T., P. Sebillon, D. Labie, J.C. Kaplan, and C. Beldjord. 1992. Rapid and direct detection of the most frequent Mediterranean beta-thalassemic mutations by multiplex allele-specific enzymatic amplification. Hum. Biol. 64: 107-113.

27. Ferrie, R.M., M.J. Schwartz, N.H. Robertson, S. Vaudin, M. Super, G. Malone, and S. Little. 1992. Development, multiplexing, and application of ARMS tests for common mutations in the CFTR gene. Am. J. Hum. Genet. 51: 251-262.

28. Fortina, P., G. Dotti, R. Conant, G. Monokian, T. Parrella, W. Hitchcock, E. Rappaport, E. Schwartz, and S. Surrey. 1992. Detection of the most common mutations causing betathalassemia in Mediterranians using a multiplex amplification refractory mutation system (MARMS). PCR Methods Applic. 2: 163-166.

29. Jawaheer, D., W.E. Ollier, and W. Thomson. 1993. Multiple ARMS-RFLP: A simple and rapid method of HLA-DR4 subtyping. Eur. I. Immunogen. 20: 175-187.

30. Chehab, F.F. and Y.W. Kan. 1989. Detection of specific DNA sequences by fluorescence amplification: A color complementation assay. Proc. Natl. Acad. Sci. 86: 9178-9182.

31. Zazzi, M., L. Romano, A. Brasini, and P.E. Valensin. 1993. Simultaneous amplification of multiple HIV-1 DNA sequences from clinical specimens by using nested-primer polymerase chain reaction. AIDS Res. Hum. Retroviruses 9: 315-320.

32. Repp, R., S. Rhiel, K.H. Heermann, S. Schaefer, C. Keller, P. Ndumbe, F. Lambert, and W.H. Gerlich. 1993. Genotyping by multiplex polymerase chain reaction for detection of endemic hepatitis B virus transmission. J. Clin. Microbiol. 31: 1095-1102.

33. Edwards, A., A. Civitello, H.A. Hammond, and C.T. Caskey. 1991. DNA typing and genetic mapping with trimeric and tetrameric tandem repeats. Am. /. Hum. Genet. 49: 746-756.

34. Ziegle, J.S., Y. Su, K.P. Corcoran, L. Nie, P.E. Maynard, L.B. Hoff, L.J. McBride, M.N. Kronick, and S.R. Diehl. 1992. Application of automated DNA sizing technology for genotyping microsatellite loci. Genomics 14: 1026-1031.

35. Gibbs, R.A., J.S. Chamberlain, and C.T. Caskey. 1989. Diagnosis of new mutation diseases using the polymerase chain reaction. In The polymerase chain reaction: Principles and Applications (ed. H. Erlich), pp. 171-192. Stockton Press, New York.

36. Beggs, A.H., M. Koenig, F.M. Boyce, and L.M. Kunkel. 1990. Detection of $98 \%$ DMD/BMD gene deletions by PCR. Hum. Genet. 86: 45-48.

37. Sunzeri, F.J., T.-H. Lee, R.G. Brownlee, and M.P. Busch. 1991. Rapid simultaneous detection of multiple retroviral DNA sequences using the polymerase chain reaction and capillary DNA chromatography. Blood 77: 879-886.

38. Vandenvelde, C., M. Verstraete, and D. Van Beers. 1990. Fast multiplex polymerase chain reaction on boiled clinical samples for rapid viral diagnosis. J. Virol. Methods 30: 215-227.

39. Richards, I.R., K. Holman, S. Lane, G.R. Sutherland, and D.F. Callen. 1991. Human chromosome 16 physical map: Mapping of somatic cell hybrids using multiplex PCR deletion analysis of sequence tagged sites. Genomics 10: 1047-1052.

40. Morsey, M. P. Ward, S. Richards, and C.T. Caskey, in preparation.

41. Runnebaum, I.B., M. Nagarajan, M. Bowman, D. Soto, and S. Sukumar. 1991. Mutations in p53 as potential markers for human breast cancer. Proc. Natl. Acad. Sci. 88: 10657-10661.

42. Bourque, S.N., J.R. Valero, J. Mercier, M.C. Lavoie, and R.C. Lavesque. 1993. Multiple polymerase chain reaction for detection and differentiation of the microbial insecticide Bacillus thuringiensis. Appl. Environ. Microbiol. 59: 523-527.

43. Manam, S.S. and W.W. Nichols. 1991. Multiple polymerase chain reaction amplification and direct sequencing of homologous sequences: Point mutation of the ras gene. Anal. Biochem. 6: $552-526$

44. Clemens, P.R., R.G. Fenwick, J.S. Chamberlain, R.A. Gibbs, M. de Andrade, R. Chakraborty, 
and C.T. Caskey. 1991. Carrier detection and prenatal diagnosis in Duchenne and Becker muscular dystrophy families, using dinucleotide repeat polymorphisms. Am. J. Hum. Genet. 49: 951-960.

45. Schwartz, J.S., J. Tarleton, B. Popovich, W.K. Seltzer, and E.P. Hoffman. 1992. Fluorescent multiple linkage analysis and carrier detection for Duchenne/Becker's muscular dystrophy. Am. J. Hum. Genet. 51: 721-729.

46. Killimann, M.W., A. Pizzuti, M. Grompe, and C.T. Caskey. 1992. Point mutations and polymorphisms in the human dystrophin gene identified in genomic DNA sequences amplified by multiplex PCR. Hum. Genet. 89: 253-258.

47. Lo, K.W., C.H. Mok, G. Chung, D.P. Huang, F. Wong, M. Chan, J.C. Lee, and K.W. Tsao. 1992. Presence of p53 mutation in human cervical carcinomas associated with HPV-33 infection. Anticancer Res. 12: 1989-1994.

48. Lohmann, D., B. Horsthemke, G. Gillessen-Kaesbach, F.H. Stefani, and H. Hofler. 1992. Detection of small RB1 gene deletions in retinoblastoma by multiplex PCR and high-resolution gel electrophoresis. Hum. Genet. 89: 49-53.

49. Picci, L., F. Anglani, M. Scarpa, and F. Zachello. 1992. Screening for cystic fibrosis gene mutations by multiplex DNA amplification. Hum. Genet. 88: 527-531.

50. O'Keefe, D.S. and A. Dobrovic. 1993. A rapid and reliable method for genotyping the ABO blood group. Hum. Mutat. 2: 67-70.

51. Vesy, C.J., J.K. Greenson, A.C. Papp, P.J. Snyder, S.J. Qualman, and T.W. Prior. 1993. Evaluation of celiac disease biopsies for adenovirus 12 DNA using a multiplex polymerase chain reaction. Mod. Pathol. 6: 61-64.

52. Serre, J.L., A. Taillandier, E. Mornet, B. Simon-Bouy, J. Boue, and A. Boue. 1991. Nearly 80\% of cystic fibrosis heterozygotes and $64 \%$ of couples at risk may be detected through a unique screening of four mutations by ASO reverse dot blot. Genomics 11: 1149-1151.

53. Chehab, F.F. and J. Wall. 1992. Detection of multiple cystic fibrosis mutations by reverse dot blot hybridization: A technology for carrier screening. Hum. Genet. 89: 163-168.

54. Shuber, A.P., J. Skoletsky, R. Stern, and B.L. Handelin. 1993. Efficient 12-mutation testing in the CFTR gene: A general model for complex mutation analysis. Hum. Mol. Genet. 2: 153158.

55. Wattel, E., M. Mariotti, F. Agis, E. Gordien, O. Prou, A.M. Courouce, P. Rouger, S. WainHobson, I.S. Chen, and J.J. Lefrere. 1992. Human T lymphotrophic virus (HTLV) type I and II DNA amplification in HTLV-I/II-seropositive blood donors of the French West Indies. J. Infect. Dis. 165: 369-372.

56. Golmolka, M., C. Epplen, J. Buitkamp, and J.T. Epplen. 1993. Novel members and germline polymorphisms in the human T-cell receptor Vb6 family. Immunogenetics 37: 257-265.

57. Nigro, N., L. Politano, G. Nigro, S.C. Romano, A.M. Molinari, and G.A. Puca. 1992. Detection of a nonsense mutation in the dystrophin gene by multiple SSCP. Hum. Mol. Genet. 1: 517520.

58. Kornreich, R. and R.J. Desnick. 1993. Fabry disease: Detection of gene rearrangements in the human alpha-galactosidase A gene by multiplex PCR amplification. Hum. Mutat. 2: 108-111.

59. Covone, A.E., F. Caroli, and G. Romeo. 1992. Screening Duchenne and Becker muscular dystrophy patients for deletions in 30 exons of the dystrophin gene by three-multiplex PCR. Am. J. Hum. Genet. 51: 675-677.

60. Worley, K.C., J.A. Towbin, X.M. Zhu, D.F. Barker, A. Ballabio, J. Chamberlain, L.G. Biesecker, S.L. Blethen, P. Brosnan, J.E. Fox, W.B. Rizzo, G. Romeo, N. Sakuragawa, W.K. Seltzer, S. Yamaguchi, and E.R.B. McCabe. 1992. Identification of new markers in Xp21 between DXS28 (C7) and DMD. Genomics 13: 957-961.

61. Beckmann, J.S. and J.L. Weber. 1991. Survey of human and rat microsatellites. Genomics 12: $627-631$.

62. Edwards, A., H.A. Hammond, L. Jin, C.T. Caskey, and R. Chakroborty. 1992. Genetic variation at five trimeric and tetrameric tandem repeat loci in four human population groups. Genomics 12: 241-253.

63. Mulley, J.C., A.K. Gedeon, S.J. White, E.A. Haan, and R.I. Richards. 1991. Predictive diagnosis of myotonic dystrophy with flanking microsatellite markers. J. Med. Genet. 28: 448-452.

64. Morral, N. and X. Estivill. 1992. Multiplex PCR amplificatiaon of three microsatellites within the CFTR gene. Genomics 51: 1362-1364.

65. Estivill, X., N. Morral., T. Cassals, and V. Nunes. 1991. Prenatal diagnosis of cystic fibrosis by multiplex PCR of mutation and microsatellite alleles. Lancet 338: 458.

66. Mutirangura, A. 1993. Multiplex PCR of three dinucleotide repeats in the Prader-Willi/Angelman critical region (15q11-q13): Molecular diagnosis and mechanism of uniparental disomy. Hum. Mol. Genet. 2: 143-151.

67. Furlong, R.A., R.G. Goudie, N.P. Carter, J.E.W. Lyall, N.A. Affara, and M.A. Ferguson-Smith. 1993. Analysis of four microsatellite markers on the long arm of chromosome 9 by meiotic recombination in flow-sorted single sperm. Am. J. Hum. Genet. 52: 1191-1199.

68. Richards, I.R., K. Holman, Y. Shen, H. Kozman, H. Harley, D. Brook, and D. Shaw. 1991. Human glandular Kallikrein genes: Genetic and physical mapping of the KLK1 locus using a 
highly polymorphic microsatellite PCR marker. Genomics 11: 77-82.

69. Huang, T.H.-M., R.W. Cottingham Jr., D.H. Ledbetter, and H.Y. Zoghbi. 1992. Genetic mapping of four dinucleotide repeat loci, DXS435, DXS45, DXS454, DXS424, on the X chromosome using the multiplex polymerase chain reaction. Genomics 13: 375-380.

70. Pfitzinger, H., B. Ludes, and P. Mangin. 1993. Sex determination of forensic samples: Coamplification and simultaneous detection of a Y-specific and an X-specific DNA sequence. Int. J. Legal Med. 105: 213-216.

71. Gannon, V.P. R.K. King, J.Y. Kim, and E.J. Golsteyn Thomas. 1992. Rapid and sensitive method for the detection of Shiga-like toxin producing bacteria in ground beef using the polymerase chain reaction. Appl. Environ. Microbiol. 58: 3809-3815.

72. Pearson, B.M. and R.A. McKee. 1992. Rapid identification of Saccharomyces cerevisiae, Zygosaccharomyces bailli and Zygosaccharomyces rouxii. Int. J. Food Microbiol. 16: 63-67.

73. Soler, C., P. Allibert, Y. Chardonnet, P. Cros, B. Matrand, and J. Thivolet. 1991. Detection of human papilloma virus types $6,11,16$, and 18 in mucosal and cutaneous lesions by the multiplex polymerase chain reaction. J. Virol. Methods 35: 143-157.

74. Toh, Y., H. Kuwano, S. Tanaka, K. Baba, H. Matsuda, K. Sugimachi, and R. Mori. 1992. Detection of human papillomavirus DNA in esophageal carcinoma in Japan by polymerase chain reaction. Cancer 70: 2234-2238.

75. Sevall, J.S. 1990. Detection of parvovirus B19 by dot-blot and polymerase chain reaction. Mol. Cell. Probes 4: 237-246.

76. Wirz, B., J.D. Traschin, H.K. Muller, and D.B. Mitchell. 1993. Detection of hog cholera virus and differentiation from other pestiviruses by polymerase chain reaction. J. Clin. Microbiol. 31: 1148-1154. 


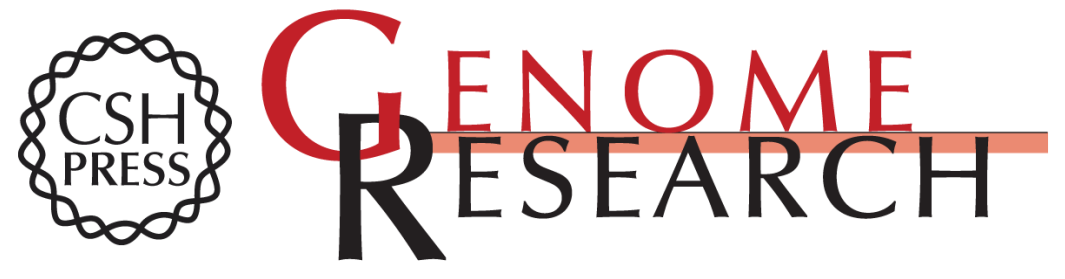

\section{Multiplex PCR: advantages, development, and applications.}

M C Edwards and R A Gibbs

Genome Res. 1994 3: S65-S75

References This article cites 71 articles, 14 of which can be accessed free at:

http://genome.cshlp.org/content/3/4/S65.full.html\#ref-list-1

\section{License}

Email Alerting Receive free email alerts when new articles cite this article - sign up in the box at the Service top right corner of the article or click here.

\section{Affordable, Accurate Sequencing.}

To subscribe to Genome Research go to: https://genome.cshlp.org/subscriptions 